\title{
THE DETERMINATION OF THE CIRCULATING BLOOD VOLUME WITH CARBON MONOXIDE
}

By H. C. CHANG' AND GEORGE A. HARROP, JR.

(From the Medical Clinic of the Johns Hopkins Hospital and University, Baltimore)

(Received for publication November 21, 1927)

\section{INTRODUCTION}

The estimation of the circulating blood volume in man is of interest in the study of a number of clinical problems. The results published by many investigators have varied widely. The principle involved in all of these studies consists in the introduction into the blood stream of a measured amount of some substance whose concentration in the circulating blood may then be estimated after complete mixing has taken place. Many materials have been employed and the literature has been reviewed in recent articles $(1,2)$. The type of substance most commonly used has been a dye whose concentration in the blood plasma is estimated with a colorimeter. The dye chiefly used is vital red, concerning which a considerable literature has appeared (3). The objections which have been raised to the use of dyestuffs may be briefly stated. Quantitative intravenous injection without extravasation is frequently difficult. Injections have been followed by serious reactions. Considerable losses may occur from the plasma through adsorption on the erythrocytes, removal by phagocytosis, and by diffusion into the lymph and other body fluids. Where alterations in capillary permeability occur in pathological conditions, as in edema, considerable amounts may penetrate rapidly into the tissues (4). For accurate colorimetric observations precautions must be taken to have the plasma clear and free from hemoglobin.

A recent reinvestigation of the problem by Lindhard appears to have revealed other difficulties. After the injection of the dye into a peripheral vein, an appreciable time interval is needed to allow complete mixing throughout the circulation. It now appears that com-

1 Jacques Loeb Fellow in Medicine. 
plete mixing does not take place in the blood stream in the three or four minutes usually allowed (5). If the subject exercises by walking and by making arm movements for a period of ten minutes after the dye injection, much lower results than have previously been reported by this method are obtained for the blood volume. As any loss of the injected dye from the blood during this period should make the apparent blood volume higher, not lower, these findings indicate that previous workers have not secured the necessary complete mixing in the circulating blood. It is further claimed that if a series of determinations are made on one individual, as is highly desirable if not indispensible in clinical studies, tolerance is produced, so that the dye disappears with increasing rapidity from the blood after four or five successive blood volume determinations are made. Larger apparent blood volume values are then obtained with each subsequent determination. This finding is at variance with the extraordinarily constant values which have been reported by others when repeated determinations of the blood volume by the dye method have been made on one individual over a considerable period (6).

The use of carbon monoxide possesses certain advantages which deserve consideration. We have particularly in mind its employment in those conditions in which the capillary permeability may be altered, and where the diffusion of dyestuffs from the plasma into the tissue spaces may be greatly accelerated. They include many of the pathological conditions in which blood volume changes may be expected and are of particular interest. The carbon monoxide method was first used in its present form by Haldane and Smith (7), and improvements were made by Douglas (8), and by Salvesen (9), working in Van Slyke's laboratory.

Carbon monoxide in sufficient amounts may be quantitatively introduced into the blood by inhalation without pain or danger. The method of introduction into the minutely divided blood stream in the lung capillaries greatly facilitates diffusion and rapid, complete mixture. The gas by reason of its affinity for hemoglobin is entirely bound, for all practical purposes, to this substance alone. The amount which is physically dissolved in other tissues is insignificant. By the gas methods described below its estimation in small quantities of blood is easily and accurately made. 
The calculation of the blood volume and of the total hemoglobin is then easily made. Knowing the amount of gas absorbed and its concentration in the blood after mixture, the blood volume is readily obtained. If the oxygen capacity is known the concentration of hemoglobin may be estimated. The blood volume multiplied by this figure will then give the total circulating hemoglobin.

\section{METHOD OF ADMINISTERING CARBON MONOXIDE}

The method employed for the administration of the gas is essentially that used by Haldane and followed by subsequent observers. A rebreathing apparatus is used consisting of a small rubber bag with glass connecting tube and rubber mouthpiece. In unconscious persons a mask with minimal dead space is used instead. The bag is filled with air and after rebreathing has commenced a measured amount of carefully purified carbon monoxide is added from a gas burette. The subject breathes back and forth into this bag through a small bottle filled with fresh soda lime to remove carbon dioxide. The bottle is placed in an ice filled jacket, in order to cool the air and to precipitate excessive moisture. Care is taken to have the total amount of gas in the bag as small as possible so that at the height of inspiration it is nearly collapsed. Oxygen is admitted to it very slowly in amounts just sufficient to balance absorption, from a large pressure tank, equipped with a needle valve. The dead space is thus reduced to a minimum. The concentration of oxygen in the bag does not exceed 30 per cent. As the tension of carbon monoxide in the blood depends on the corresponding partial pressure of oxygen, this precaution is necessary in order that the carbon monoxide may be absorbed as completely as possible in the lungs. The total volume of the gas in the system at the moment of complete normal expiration does not usually exceed $2500 \mathrm{cc}$. A side tap is placed in the connection between bag and absorber so that a sample of gas may be taken just before the conclusion of the experiment or whenever desirable, to check the concentration in the bag. Before such a gas sample is to be removed, the oxygen supply is completely shut off and ten or twelve respirations into the closed system are taken in order to obtain complete mixture of gas between lungs and apparatus.

The subject breathes to and fro into the bag for a period of twenty 
minutes. At the end of this time a blood sample without stasis is taken from an arm vein. Aside from the venapuncture, no pain or discomfort whatever is experienced.

\section{METHOD OF ANALYZING BLOOD SAMPLES}

The blood samples for carbon monoxide analysis are collected in oiled syringes and placed in bottles, containing dry oxalate under oil. The samples are analyzed without delay.

We have employed two methods for the analysis. The first is an elaboration of the procedure used by Barcroft and his associates (10). An accurately measured $5 \mathrm{cc}$. sample of the thoroughly mixed blood is introduced into the extraction chamber of a Van Slyke constant pressure apparatus and $15 \mathrm{cc}$. of completely extracted acid ferricyanide solution are added. After the solution is shaken for twenty minutes, the liquid is removed as far as possible into the side arm of the apparatus, and the extracted gas (about $3 \mathrm{cc}$.) is transferred with several washings into a Krogh gas analysis apparatus of suitable construction provided with a combustion chamber. Estimations of the carbon monoxide are made with an accuracy of about 0.005 per cent. A comparison of the volume of carbon monoxide lost in combustion is then made with the volume of carbon dioxide formed. The agreement is usually very close. The temperature is estimated with a thermometer suspended in the water bath surrounding the gas pipette and thermobarometer. The total volume of carbon monoxide present, corrected by the addition of the amount left dissolved in the fluid from which it was extracted (as calculated from the basic equation of Van Slyke, 1924) (11), is then readily obtained.

The second method is that of Van Slyke and Robbins (12) to which our attention was kindly drawn by Dr. Van Slyke after the above procedure was elaborated and in use. This also requires the use of a 5 cc. blood sample, which is analyzed by the absorption of oxygen (pyrogallol) and then of carbon monoxide (Winkler's reagent) in the Van Slyke-Harrington constant volume pipette. The agreement of results obtained by these two different procedures is satisfactory. (Table 1.) Calibration of the Van Slyke-Harrington pipette for this determination requires care, the final volume read being $0.5 \mathrm{cc}$.

We have made a number of blood volume estimations upon normal 
TABLE 1

Comparison of results obtained by extraction and combustion analysis with those obtained by the method of Van Slyke and Robbins

\begin{tabular}{c|c|c}
\hline & $\begin{array}{c}\text { Extraction in vacuo and } \\
\text { combustion }\end{array}$ & Van Slyke-Robbins method \\
\cline { 3 - 3 } 1 & 2.62 & 2.63 \\
2 & 2.55 & 2.54 \\
3 & 1.79 & 1.85 \\
4 & 2.08 & 1.98 \\
5 & 2.59 & 2.59 \\
6 & 2.33 & 2.25 \\
7 & 2.25 & 2.25 \\
8 & 2.34 & 2.35 \\
9 & 1.34 & 1.42 \\
10 & 3.09 & 3.11 \\
11 & 2.68 & 2.58 \\
12 & 1.63 & 1.68 \\
13 & 2.23 & 2.26 \\
14 & 1.44 & 1.48 \\
\hline
\end{tabular}

TABLE 2

Blood volume of normal young men and young women-ages 23 to 35 years

(All of these determinations were made in the months of December, January and February, in the early afternoon, about one hour after a light lunch.)

\begin{tabular}{|c|c|c|c|c|c|c|c|c|c|}
\hline \multirow[t]{2}{*}{ Number } & \multirow[t]{2}{*}{ Subject } & \multirow[t]{2}{*}{ Sex } & \multirow{2}{*}{$\frac{\text { Weight }}{\text { kgm. }}$} & \multirow{2}{*}{$\begin{array}{c}\begin{array}{c}\text { Circulat- } \\
\text { ing } \\
\text { blood } \\
\text { volume }\end{array} \\
c c .\end{array}$} & \multicolumn{2}{|c|}{ Blood volume } & \multirow{2}{*}{$\begin{array}{c}\begin{array}{c}\text { Red } \\
\text { blood } \\
\text { cells }\end{array} \\
\begin{array}{c}\text { millions } \\
\text { per } \\
\text { cu. mm. }\end{array}\end{array}$} & \multirow{2}{*}{$\begin{array}{c}\begin{array}{c}\text { Oxygen } \\
\text { capacity }\end{array} \\
\begin{array}{c}\text { oolumes } \\
\text { per cent }\end{array}\end{array}$} & \multirow{2}{*}{$\begin{array}{c}\begin{array}{c}\text { Cell } \\
\text { volume }\end{array} \\
\text { per cent }\end{array}$} \\
\hline & & & & & $\begin{array}{l}\text { cc. per } \\
\text { kgmm } \\
\text { weight }\end{array}$ & $\begin{array}{l}\text { c. per } \\
\text { s.. m. } \\
\text { suifface }\end{array}$ & & & \\
\hline 1 & W. & M. & 72.4 & 4,690 & 64.8 & 2,510 & 4.8 & 18.4 & 40.0 \\
\hline 2 & G. G. & M. & 67.0 & 4,720 & 69.6 & 2,660 & 5.8 & 20.8 & 42.0 \\
\hline 3 & D. & M. & 87.3 & 5,610 & 64.9 & 2,690 & 4.9 & 21.0 & 42.0 \\
\hline 4 & E. H. & M. & 71.4 & 5,410 & 75.5 & 2,860 & 4.4 & 20.2 & 40.8 \\
\hline 5 & E. H. H. & M. & 73.6 & 4,740 & 64.4 & 2,550 & 5.3 & 20.6 & 43.5 \\
\hline 6 & H. C. & M. & 65.8 & 4,710 & 71.5 & 2,720 & 5.1 & 20.7 & 39.5 \\
\hline 7 & W. A. P. & M. & 75.4 & 4,760 & 63.4 & 2,540 & 5.0 & 18.1 & 40.5 \\
\hline 8 & B. L. & M. & 83.1 & 5,260 & 63.4 & 2,710 & 5.8 & 20.8 & 42.5 \\
\hline 9 & C. $\mathrm{K}$. & F. & 55.6 & 3,455 & 64.5 & 2,200 & 4.3 & 18.0 & 40.0 \\
\hline 10 & E. N. & F. & 52.6 & 3,460 & 65.7 & 2,380 & 4.5 & 19.1 & 41.0 \\
\hline 11 & L. W. & F. & 51.1 & 3,618 & 71.8 & 2,365 & 4.6 & 17.8 & 39.5 \\
\hline 12 & R. & F. & 53.4 & 3,415 & 65.4 & 2,280 & 4.7 & 20.4 & 43.0 \\
\hline 13 & DeH. & F. & 50.7 & 3,360 & 69.0 & 2,385 & 4.1 & 19.2 & 39.5 \\
\hline 14 & S. & F. & 54.8 & 3,185 & 60.4 & 1,990 & 4.6 & 18.3 & 40.2 \\
\hline 15 & N. & F. & 58.6 & 3,680 & 62.8 & 2,260 & 4.4 & 20.9 & 41.5 \\
\hline 16 & Rv. & F. & 63.2 & 4,360 & 68.9 & 2,480 & 4.5 & 17.6 & 40.0 \\
\hline
\end{tabular}


individuals (table 2). We have been unable to detect any alterations in the blood volume due to the menstrual cycle in normal women.

The ability to estimate carbon monoxide in blood with an accuracy of about 0.1 volumes per cent is of advantage because it reduces the amount of gas which must be administered in order to obtain a sufficient blood concentration for satisfactory blood gas analysis. Amounts in excess of $200 \mathrm{cc}$. have been used by Haldane and by Douglas, and about $150 \mathrm{cc}$. by Plesch (13) and by Salvesen. We use from 90 to $110 \mathrm{cc}$. for the normal adult of average weight, and proportionately less for lighter individuals. We have summarized the results obtained

TABLE 3

Comparison of average results for the blood volume obtained by various observers, using the carbon monoxide method

\begin{tabular}{|c|c|c|c|c|c|c|c|c|}
\hline \multirow{2}{*}{ Author } & \multirow{2}{*}{ 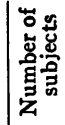 } & \multirow{2}{*}{$\mid \begin{array}{c}\text { Amount } \\
\text { of } \\
\text { gas } \\
\text { inhaled }\end{array}$} & \multirow{2}{*}{$\underset{\text { time }}{\text { Mixing }}$} & \multicolumn{2}{|c|}{ Blood volume } & \multicolumn{3}{|c|}{ Blood volume } \\
\hline & & & & $\underset{\text { mum }}{\text { Maxi- }}$ & $\underset{\text { mum }}{\text { Mini- }}$ & $\underset{\text { mum }}{\text { Maxi- }}$ & $\underset{\text { mum }}{\text { Mini- }}$ & Average \\
\hline - & & $c c$. & minutes & $c c$. & $c c$. & $\begin{array}{l}\text { cc. per } \\
\text { kgm. } \\
\text { body } \\
\text { weight }\end{array}$ & $\begin{array}{l}\text { cc. per } \\
\text { kgm. } \\
\text { body } \\
\text { weight }\end{array}$ & \begin{tabular}{|c|c} 
cc. per \\
$k g m$. \\
body \\
weight
\end{tabular} \\
\hline Haldane-Smith. & 12 & \pm 200 & 3 & 4,450 & 2,750 & 62.7 & 39.5 & 47.8 \\
\hline Dor & 2 & \pm 200 & \pm 20 & 5,583 & 4,637 & 79.8 & 71.7 & \\
\hline opredit & 4 & \pm 200 & $20-35$ & 4,821 & 4,075 & \multicolumn{3}{|c|}{ No weights given } \\
\hline Plesc & 8 & \pm 175 & $16-34$ & 4,737 & 3,605 & 60.5 & 50.2 & 53.2 \\
\hline Smith et al. (14). & 6 & $\pm 4^{*}$ & $8-10$ & 4,633 & 3,875 & 74.0 & 62.6 & 68.1 \\
\hline Salvesen. & 6 & \pm 160 & $10-15$ & 4,601 & 3,464 & 69.9 & 52.3 & 59.5 \\
\hline
\end{tabular}

* Cubic centimeters per kilogram body weight.

by other observers (table 3). Haldane and Smith, and Douglas made analyses of carbon monoxide in blood with the method of carmine titration, a procedure which others have found unsatisfactory.

The methods used in the present study for the analysis of carbon monoxide in blood are so sensitive that the quantities of the gas which are inhaled and fixed in the hemoglobin in subjects who are only moderate tobacco users may introduce considerable error if not properly corrected by a preliminary control blood analysis. The blood of persons remaining indoors all day in the winter, especially in buildings heated with soft coal also may contain very appreciable amounts of carbon monoxide even if smoking is not indulged in. 
Such a preliminary examination of the blood for combustible gas is therefore highly desirable and has in fact been made in most of our estimations and always where there was any reason to suppose that a contamination might exist.

\section{SOURCES OF ERROR IN THE TECHNICAL PROCEDURE}

The measurement of the amount of carbon monoxide inhaled may be made with a probable error not exceeding $0.5 \mathrm{cc}$. The average amount of gas used is $100 \mathrm{cc}$., so that the greatest error is 0.5 per cent. The amount of carbon monoxide in the blood sample can be estimated with an error of about 0.1 volumes per cent. Duplicates usually agree within 0.06 volumes per cent. Since the amount measured is ordinarily between 2 and 3 volumes per cent, the maximum error is between 3.3 and 5 per cent. These errors are not likely to be additive. Consequently the maximal error in the technical procedures does not exceed 5 per cent and is probably less.

The amount of gas left in the bag and absorbing bottle is very small. It appears to have been neglected by the earlier workers (Haldane and Smith, Douglas). A somewhat elaborate procedure was worked out by Salvesen for its correction. We have preferred to standardize our technique by reducing the oxygen content of the inhaled mixture as much as possible and by reduction of the dead space of the breathing system. Numerous gas samples taken toward the end of our experiments have yielded values between 0.015 and 0.03 per cent carbon monoxide. The volume of the system (bottle, bag and tubing) is approximately $1500 \mathrm{cc}$., and to this must be added the pulmonary volume and dead space, say about $3000 \mathrm{cc}$., or in all $4500 \mathrm{cc}$. The maximum carbon monoxide gas unabsorbed therefore in our experiments is $1.35 \mathrm{cc}$. and the minimum is about $0.7 \mathrm{cc}$. If $1.0 \mathrm{cc}$. is subtracted, therefore, the maximum error should not exceed 0.33 per cent in a total carbon monoxide absorption of $100 \mathrm{cc}$. We believe attempts at closer approximation are unnecessary as well as fallacious unless the phase of respiration at the moment of taking the gas sample, and the exact lung volumes are also known. Due to mouth breathing in persons unaccustomed to a nose clip, the tidal air may well be $800 \mathrm{cc}$. or even 1000 cc., about 20 per cent or more of the volume of the total system. At first we used a small recording spirometer in order to be 
able to measure the amount and phase of the respirations very accurately, but it shortly became evident that this procedure was unnecessary.

\section{DISCUSSION OF THE METHOD}

The most important objections which have been raised against the use of carbon monoxide in measuring the circulating blood volume are, in the first place, the unknown loss which may occur due to diffusion from the blood into the hemoglobin of the muscle, and, in the second place, the uncertainty as to the uniformity of distribution of the gas among the blood corpuscles themselves. The latter question really resolves itself into the problem of the evenness of distribution of erythrocytes with respect to plasma throughout the circulation, for it is hardly conceivable that even distribution of the gas in the hemoglobin of the erythrocytes themselves is incomplete after twenty minutes. Unfortunately, it is not possible at the present time to give a definite answer to either criticism, but we think it is possible to define the maximum error which may thus be caused in blood volume estimations. If this source of error is kept in mind, it is clearly valid to apply the technique to studies in normal and pathological conditions.

The question of the identity and quantity of hemoglobin in muscle has occupied the attention of physiologists for many years. Gescheidtlen (15) long ago indicated that muscle hemoglobin does not exceed 5 per cent of the total blood hemoglobin, and a value of this magnitude has been commonly accepted. Whipple and his coworkers (16) now state, however, that the total muscle hemoglobin in dogs may amount to from 10 to 80 per cent of the circulating hemoglobin. They believe that "muscle hemoglobin is concerned with the rapid exchange of oxygen and carbon dioxide between the blood and contracting elements."

Without entering into a discussion of these figures, or of the technical procedures on which they are based, it is evident that an index of the amount of carbon monoxide which will diffuse into muscle from the circulating blood may be obtained by a study of the drop in carbon monoxide concentration in the blood which occurs in the transition from rest to vigorous muscular exercise. The capillary bed in 
the working muscles under these conditions is increased many fold, and contains a much larger proportion of the circulating blood volume, while at the same time the blood flow is greatly augmented. Under such circumstances complete saturation of muscle hemoglobin should occur, the carbon monoxide concentration in the blood should drop, and the figure obtained for blood volume must be higher by the amount which has diffused into the muscle tissues. The increased cardiac output per minute with exercise will produce more even mixing of the cells.

For the reason just mentioned six exercise experiments on four normal subjects were performed in the following way after a period of thirty minutes of complete rest. Each subject, sitting at ease on

TABLE 4

The effect of exercise on the apparent blood volume and percentage of carbon monoxide in the blood

\begin{tabular}{|c|c|c|c|c|}
\hline Date & Subject & $\begin{array}{c}\text { Resting blood } \\
\text { CO }\end{array}$ & $\begin{array}{l}\text { After exercise } \\
\text { blood CO }\end{array}$ & $\begin{array}{c}\text { Percentile } \\
\text { change in } \\
\text { blood volume }\end{array}$ \\
\hline - & & volumes per cent & oolumes per cent & \\
\hline November $16 \ldots \ldots \ldots \ldots \ldots$ & H. C. C. (a) & 2.08 & 1.94 & +7.1 \\
\hline January $3 . . . . . .$. & H. C. C. (b) & 2.59 & 2.41 & +7.3 \\
\hline November $18, \ldots \ldots \ldots \ldots$ & G. A. H. (a) & 2.52 & 2.46 & +4.9 \\
\hline December $31 . . . . . .$. & G. A. H. (b) & 2.25 & 2.09 & +6.6 \\
\hline November $22, \ldots \ldots \ldots$ & E. H. & 2.40 & 2.32 & +1.3 \\
\hline November $30 . . . . . . .$. & G. G. & 2.76 & 2.63 & +2.6 \\
\hline
\end{tabular}

a bicycle ergometer, inhaled a measured amount of carbon monoxide through a circulating system provided with valves and soda lime. Blood samples for carbon monoxide analysis were taken at the end of fifteen and of twenty minutes. These had the same carbon monoxide content indicating that a condition of equilibrium must have been reached. The subject, still breathing into the closed system, then exercised very vigorously with arm and leg muscles for six to ten minutes. At the end of this time a final blood sample was taken for analysis

In three of these experiments (table 4) the change in carbon monoxide concentration after exercise was so slight as to be within the limits of error of the method, whereas in the other three, a just appre- 
ciable although definite drop occurred. This may be interpreted as due to slightly more complete diffusion of the gas into the muscle hemoglobin, or, on the other hand, to the additional red blood cell mass thrown from the spleen into the circulation with exercise, which Barcroft (17) estimates may amount to about $200 \mathrm{cc}$. in the normal individual, or about 4 to 5 per cent of the whole blood volume. The striking point is the extraordinarily slight change in the concentration of carbon monoxide in the blood produced by exercise.

The results offer no support to the suggestion that the carbon monoxide method gives results which are too low because of incomplete mixing in the smaller vessels containing an axial stream, and in which there is stagnant plasma in the "still spaces" at the periphery (18). With severe exercise more complete mixing should take place, but since no significant change occurs it seems clear that complete mixing must already have been accomplished.

The fact seems to be established that the effect of exercise is in fact not dilution but concentration both of erythrocytes and hemoglobin, a result which is plausibly explained if the red cell stores thrown out from the spleen and possibly from other sources is taken into consideration. The exercise experiments of Whipple and his co-workers (19), who found no change in blood volume after short exercise in dogs are in agreement with the above results. Broun (20) found no significant change in plasma volume, but an initial increase in cell volume and in "circulating blood pigment" as a result of brief exercise. With the exception of the work of Lindhard above cited, we have not found any record of previous studies of the blood volume in man during exercise.

We believe that the experiments described offer substantial evidence that the estimates of blood volume obtained with the present technique are maximal figures. They are too high by the amount of carbon monoxide which has escaped into the muscle hemoglobin. There is no doubt that the twenty minute rebreathing interval has afforded quite sufficient time for equilibrium to be reached with the muscle tissues. Nevertheless we have avoided shorter intervals because of the possibility of incomplete and uncertain mixing. Several experiments were made in attempts to estimate the minimal complete mixing time (fig. 1). It is seen that the curves rise at different rates 
although a plateau indicating complete mixing is reached in all at the end of fifteen to seventeen minutes. We have no explanation to offer for the individual differences in the mixing time required and we have preferred to standardize our technique by continuing rebreathing until equilibrium is certainly established.

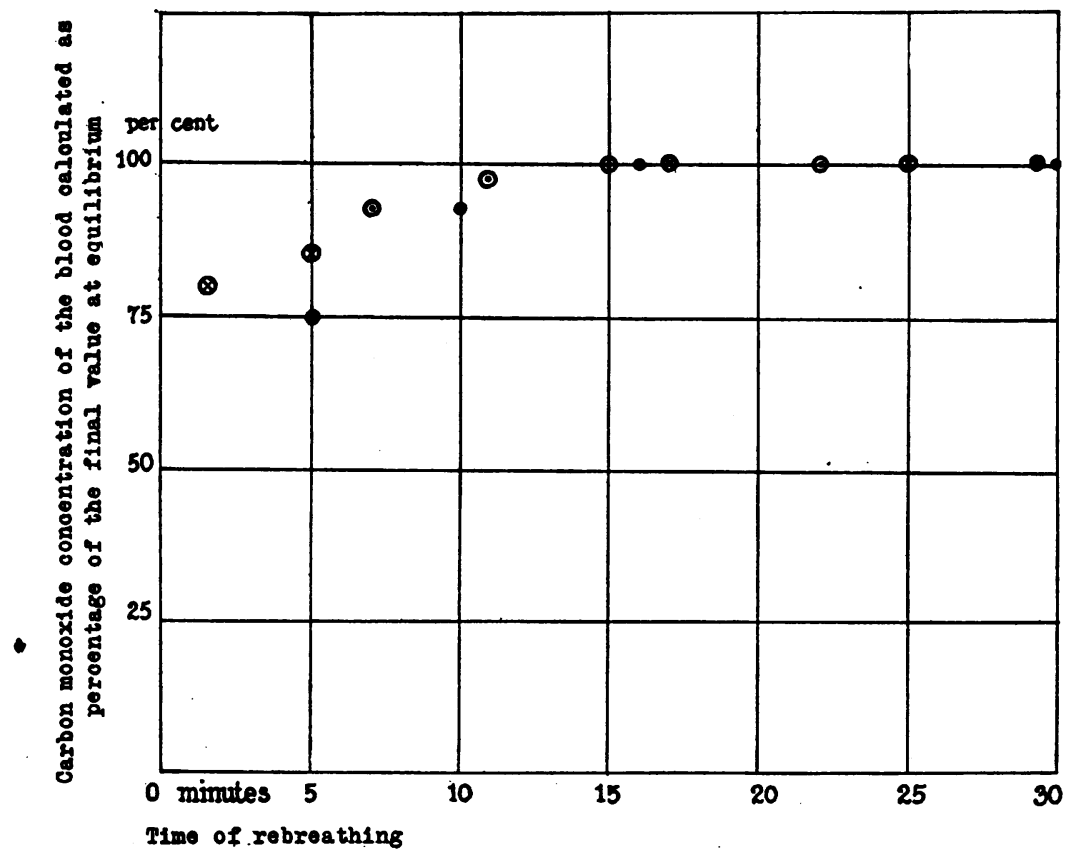

Chart 1. Shows the Tme Required after Inhalation Commences to SeCURe CoMplete Muxture

Each series of designations represents one experiment. Experiment I. $\otimes$ Experiment II. $\odot$ Experiment III.

The fact that nearly all blood volume measurements in human subjects by the dye methods are from 20 to 50 per cent higher than those obtained by the carbon monoxide method, even though the latter according to the technique which we have employed must be maximal values, may be explained in large part on the grounds of insufficient mixing of the dye in the blood, as Lindhard has recently shown, in the brief interval usually allowed. The escape of the dye 
into the lymph and tissue fluids, as well as the activity of phagocytes may also be factors of importance (21).

\section{SUMMARY}

1. A method for the estimation of the circulating blood volume in man is described. It consists in the inhalation of a measured amount of carbon monoxide and the subsequent estimation of its concentration in the circulating blood. The maximal error in the technical procedures involved does not exceed five per cent.

2. The circulating blood volume has been found by this method in sixteen normal individuals to lie between 60.4 and $75.5 \mathrm{cc}$. per kilogram of body weight.

3. The circulating blood volume when expressed as cubic centimeters per square meter of body surface in these individuals varied between 1990 and $2860 \mathrm{cc}$.

4. The sources of error of the carbon monoxide method are discussed and the probable reasons are stated for the discrepancies in the results as compared with those of the dye methods.

\section{BIBLIOGRAPHY}

1. Seyderhelm, R., and Lampe, W., Ergeb. d. inn. Med. u. Kinderh., 1925, xxvii, 245. Die Blutmengenbestimmung und ihre klinische Bedeutung.

2. Erlanger, J., Physiol. Rev., 1921, i, 177. Blood Volume and Its Regulation.

3. Keith, N. M., Rowntree, L. G., and Geraghty, J. T., Arch. Int. Med., 1915, xvi, 547. A Method for the Determination of Plasma and Blood Volume.

4. (a) Krogh, A., and Harrop, G. A., Proc. Physiol. Soc. J. Physiol., 1921, liv, p. cxxv. Some Observations on Stasis and Edema.

(b) Fröhlich, A., and Zak, E., Zeits. f. d. gen. exp. Med., 1924, xlii, 41. Mikroskopische Studien am peripheren Kreislaufe von Kalt- und Warmblütern.

5. Lindhard, J., Am. J. Physiol., 1926, lxxvii, 669. A Dye Method for Determining the Blood Volume in Man.

6. Thompson, W. O., J. Clin. Invest., 1926, ii, 477. Studies in Blood Volume. I. The Blood Volume in Myxedema, with a Comparison of Plasma Volume Changes in Myxedema and Cardiac Edema.

7. Haldane, J., and Smith, J. L., J. Physiol., 1899-1900, xxv, 331. The Mass and Oxygen Capacity of the Blood in Man.

8. Douglas, C. G., J. Physiol., 1910, xl, 472. The Determination of the Total Oxygen Capacity and Blood Volume at Different Altitudes by the Carbon Monoxide Method. 
9. Salvesen, H. A., J. Biol. Chem., 1919, xl, 109. The Determination of Blood Volume by the Carbon Monoxide Method.

10. Barcroft, J., Binger, C. A., Bock, A. V., Doggart, J. H., Forbes, H. S., Harrop, G., Meakins, J. C., and Redfield, A. C., Phil. Trans. Roy. Soc. B., 1922, ccxi, 351. Observations upon the Effect of High Altitude on the Physiological Processes of the Human Body, Carried out in the Peruvian Andes, Chiefly at Cerro de Pasco. Report to the Peru High-Altitude Committee.

11. Van Slyke, D. D., and Neill, J. M., J. Biol. Chem., 1924, lxi, 523. Determination of Gases in Blood and Other Solutions by Vacuum Extraction and Manometric Measurement. I.

12. Van Slyke, D. D., and Robbins, F. S., J. Biol. Chem., 1927, lxxii, 39. The Gasometric Determination of Small Amounts of Carbon Monoxide in Blood, and Its Application to Blood Volume Studies.

13. Plesch, J., Zeits. f. exper. Path. u. Therap., 1909, vi, 380. Hämodynamische Studien.

Plesch, J., Zeits. f. klin. Med., 1922, xciii, 241. Untersuchungen über die Physiologie und Pathologie der Blutmenge.

14. Smith, H. P., Belt, E., Arnold, H. R., and Carrier, E. B., Am. J. Physiol., 1924, lxxi, 395. Blood Volume Changes at High Altitudes.

15. Gscheidlen, R., Untersuchungen aus dem physiologischen Laboratorium in Würzburg., Leipzig, 1869, 2. Th., 143. Studien über die Blutmenge und ihre Vertheilung im Thierkörper.

Gscheidlen, R., Pflügers, Arch. 1878, vii, 530 (Leipzig). Bemerkungen zu der Welcker'schen Methode der Blutbestimmung und der Blutmenge einiger Säugethiere.

16. Whipple, G. H., Am. J. Physiol., 1926, lxxvi, 685, 693, 708. The Identity of Muscle Hemoglobin and Blood Hemoglobin. The Hemoglobin of Striated Muscle. I and II.

17. Barcroft, J., Harris, H. A., Orahovats, D. and Weiss, R., J. Physiol., 1925, $\mathrm{lx}, 443$. A Contribution to the Physiology of the Spleen.

18. Smith, H. P., Arnold, H. R., and Whipple, G. H., Am. J. Physiol., 1921, lvi, 336. Blood Volume Studies. VII. Comparative Values of Welcker, Carbon Monoxide and Dye Methods for Blood Volume Determinations.

19. Lee, F. W., Carrier, E. B., and Whipple, G. H., Am. J. Physiol., 1922, lxi, 149. Simultaneous Determinations of Plasma and Hemoglobin Volumes.

20. Broun, G. O., J. Exp. Med., 1922, xxxvi, 481. Blood Destruction During Exercise. I. Blood Changes Occurring in the Course of a Single Day of Exercise.

21. Smith, H. P., Bull., J. H., Hosp., 1925, xxxvi, 325 and 1925, xxxvii, 177. The Fate of an Intravenously Injected Dye with Special Reference to its Use in Blood Volume Determination. Intravenous Injections of Fluid and Repeated Blood Volume Determination. 